\title{
85623 - UM TEMPO PARA UMA PROSA: IDOSOS EM SITUAÇÃO DE RUA NO CONTEXTO BRASILEIRO
}

\author{
Pôster - Gerontologia
}

Isaac Guimarães dos Santos / Santos, IG / UESC; João Luis Almeida da Silva / Silva, JLA / UESC

Introdução: o aumento da expectativa de vida no Brasil tem gerado diversas repercussões na qualidade da assistência a pessoa idosa, com reflexo nos campos da saúde, social e político. Aqueles em situação de rua estão mais expostos à violência e à criminalidade com acesso precário a serviços sociais e de saúde (MATTOS, R.M.; FERREIRA, R.F., 2005). Objetivo: analisar o contexto dos idosos em situação de rua no Brasil. Métodos: revisão integrativa nas bases de dados: Literatura Latino-Americana e Do Caribe de Informação em Ciências da Saúde (LILACS) e Scientific Electronic Library Online (SciELO). Critérios de inclusão: artigos científicos que abordassem o contexto brasileiro do idoso em situação de rua no período de 1997 a 2017 . Uso dos descritores: "idoso"; "situação de rua" e sua variante "morador de rua". Encontrados 10 artigos e selecionados 5 - demais não correspondiam ao critério de inclusão. Resultados: obras trazem um quantitativo maior de homens; vida sexual ativa mesmo na condição de idoso; classe baixa; cerca de $10 \%$ ainda com vínculo familiar; baixa escolaridade; funções profissionais informais; distorção na percepção de doença; vivência em ambiente hostil e sub-humano (ROSA, A.S.; CAVICCHIOLI, M.G.S.; BRÊTAS, A.C.P., 2006) . Como consequências: baixo autoestima, déficit de higiene, dificuldade de reinserção social (FERNANDES, F.S.L.; RAIZER, M.V.; BRÊTAS, A.C.P., 2007). Conclusão: contexto brasileiro com pouca produção de pesquisas relacionadas ao tema do idoso e situação de rua. Autores direcionam-se na mesma linha de causalidade da situação de rua do idoso: dificuldades de inserção no mercado de trabalho, dificuldades financeiras e rompimento de vínculos familiares, assim, é fundamental a participação da comunidade e apoio do Estado para investimentos em estratégias que visem melhorar a qualidade de vida e saúde da população idosa de rua.

Palavras-chave: Idoso; Pessoas em situação de rua; Condições sociais.

Referências: MATTOS, R.M.; FERREIRA, R.F. O idoso em situação de rua: Sísifo revisitado. Campinas (SP): Estudos de Psicologia. V. 1, n. 22. P. 23-32. 2005. ROSA, A.S.; CAVICCHIOLI, M. G. S.; BRÊTAS, A. C. P. O cuidado em situação de rua: revendo o significado do processo saúdedoença. Revista Brasileira de Enfermagem. V. 59, n.3. p. 331-336. 2006. FERNANDES, F. S. L.; RAIZER, M. V.; BRÊTAS, A.C.P. Pobre, idoso na rua: uma trajetória de exclusão. Revista Latino-americana. n.15, p. 110-116. 2007. 